\title{
АНАЛИЗ ПЛОТНОСТИ РОБОТОВ В АВТОМОБИЛЬНОЙ ПРОМЫШЛЕННОСТИ
}

\author{
Дубинина В.В.
}

В данной статье рассматривается зависимость плотности роботов в автомобильной промышленности от макроэкономических показателей, а также влияние, оказываемое роботизаџией, на производство автомобилей в США, Германии и Японии.

DOI: $10.20537 /$ mce2020econ11

Введение. Промышленные роботы (ПР) помогают снизить потери сырья, оптимизировать эксплуатационные расходы и повысить производительность труда. Они улучшают качество и надежность продукции, обеспечивают лучшее использование производственных площадей, а также повышают безопасность на рабочем месте.

К достоинствам промышленных роботов относятся: доступность, предсказуемость, надежность, точность и непроницаемость для агрессивных сред. Однако они пока не обладают несколькими важными способностями, которые естественным образом проявляются у людей: способность реагировать на непредвиденные обстоятельства или изменяющуюся среду, а также способность повышать производительность на основе предыдущего опыта [1].

В связи с постоянным развитием технологий применение роботов значительно расширилось. Если раньше наибольшим спросом промышленные роботы пользовались в автомобильной и электронной промышленности, то в настоящее время они находят применение в медицине, пищевой, аэрокосмической и других отраслях [2]. Тем не менее, автомобильная промышленность является ведущим потребителем промышленных роботов. Она одной из первых внедрила робототехнику на своих производствах.

Целью работы является анализ факторов, влияющих на применение и распространение промышленных роботов в автомобильной промышленности; а также моделирование зависимости плотности роботов в автомобильной промышленности от макроэкономических показателей. 
Использование роботов в автомобильной промышленности. В автомобильной промышленности наибольшая плотность роботов на 10 тыс. занятых на производстве. Плотность роботизации характеризует использование роботов в отраслях промышленности. В данной работе исследуется плотность роботизации в автомобильной промышленности, которая рассчитывается как количество промышленных роботов (ед.) на 10 тыс. занятых в автомобильной промышленности.

В настоящее время роботы в автомобильной промышленности применяются в таких областях, как сварка (точечная и дуговая), покраска, нанесение клея и герметика и многих других $[3,4]$. Они широко используются для окраски на автосборочных заводах, для нанесения покрытий (грунтовки, клея и др.). Например, роботы ABB IRB 5320 и IRB 5330 применяются для покраски на заводах компаний Fiat, BMW, Volvo, Honda, Great Wall Automobile, IRB 5400 - в компании Liaoyuan [5], IRB 580 - Euroform [6], роботы Kuka - на заводах Porsche и Mercedes Benz, Kawasaki - на заводе Toyota.

Именно автомобильная промышленность впервые начала использовать промышленные роботы в сварочных процессах. Примерно 20\% всех ПР применяются для выполнения сварочных операций. Например, роботы Fanuc используются для сварки на заводах компаний Hyundai, Nissan, a pоботы Kuka - на заводах Ford, Porsche, Mercedes Benz, Skoda, Volkswagen.

Роботы, используемые для сборочных процессов, помогают сократить потери и уменьшить время ожидания и переключения; повысить точность, согласованность и скорость конвейера, заменить людейоператоров в утомительной работе на конвейере. Например, роботы используются для установки ветровых стекол и колес. На многих заводах по производству автомобильных деталей роботы собирают узлы меньшего размера, такие как насосы и двигатели.

Погрузочно-разгрузочные роботы используются для перемещения, упаковки и подбора продукции. Они также могут автоматизировать функции, связанные с переносом деталей с одного оборудования на другое. Прямые затраты на рабочую силу снижаются, а многие утомительные и опасные виды деятельности, традиционно выполняемые людьми, исключаются.

На заводе Audi для погрузочно-разгрузочных работ используется робот Fanuc M-900iA/350, а для проверки сварных швов — Fanuc CR7iA/L. Для выполнения погрузочно-разгрузочных работ в компании 
Volkswagen Group (занимается производством стоп-сигналов) применяется робот Staubli SCARA TS60.

В 2005 г. 90\% всех промышленных роботов приходилось на автомобильную промышленность, а в 2019 г. - 50\%. Это связано с тем, что почти в каждой отрасли открываются инновационные способы внедрения роботов. Однако автомобильная промышленность продолжает доминировать в использовании роботов. Автоматизация необходима для безопасности, качества и производительности.

В 2005-2008 гг. ежегодные продажи роботов были примерно постоянными, в 2009 г. в результате экономического и промышленного кризиса продажи сократились до 19.3 тыс. ед. В 2012 г. в автомобильной отрасли продажи роботов росли в среднем на 6\%. В 2013 г. они составляли 69.4 тыс. ед., в 2015 г. насчитывалось 98 тыс. ед. (38.75\% от общего применения ПР в мире); в 2017 г. мировые продажи составили 125 тыс. ед. (рост на 21\%, табл. 1).

Таблица 1. Ежегодные мировые продажи промышленных роботов для автомобильной промышленности, шт., 2011-2017 гг. Источник: IFR [7].

\begin{tabular}{|l|c|c|c|c|c|c|c|}
\hline \multicolumn{1}{|c|}{ Показатель } & $\mathbf{2 0 1 1}$ & $\mathbf{2 0 1 2}$ & $\mathbf{2 0 1 3}$ & $\mathbf{2 0 1 4}$ & $\mathbf{2 0 1 5}$ & $\mathbf{2 0 1 6}$ & $\mathbf{2 0 1 7}$ \\
\hline $\begin{array}{l}\text { Автомобиль- } \\
\text { ная промыш- } \\
\text { ленность }\end{array}$ & 59700 & 63200 & 69400 & 94000 & 98000 & 103300 & 125000 \\
\hline $\begin{array}{l}\text { Индекс роста } \\
\text { продаж ПР, } \\
2011 \text { г. }=100 \%\end{array}$ & 100 & 106 & 116 & 157 & 164 & 173 & 209 \\
\hline
\end{tabular}

Количество выпущенных автомобилей за 10 лет выросло с 66 млн. ед. (2005 г.) до 91.5 млн. ед. (2015 г.). С увеличением количества промышленных роботов в автомобильной промышленности в мире за десять лет производство автомобилей увеличилось на 40\%. Поскольку автоматизация производственных процессов в автомобильной промышленности, таких как сварка корпуса, покраска, сборка и контроль качества приводят к сокращению времени обработки и увеличению производства автомобилей [8].

С 2010 г. спрос на роботов значительно ускорился из-за тенденции к автоматизации производства. В 2017 г. в автомобильной отрасли продажи роботов выросли более чем в 2 раза, по сравнению с 2011 г. Боль- 
ше всего роботов в 2017 г. было продано в Китае - 138 тыс.ед. (в Южной Корее - 40 тыс. ед., в Японии — 38 тыс. ед.).

Автомобильная промышленность является самым главным потребителем роботов, как с точки зрения абсолютного количества единиц роботов, так и с точки зрения плотности роботов на одного работника. Уровень автоматизации в автомобильной промышленности намного выше, чем во всех других секторах экономики. Наибольшая плотность роботов в 2017 г. была у Южной Кореи - 2435 роботов на 10 тыс. занятых. В России данный показатель составляет примерно 4 ед. (см. табл. 2).

Таблица 2. Плотность роботизации в автомобильной промышленности по странам. Источник: IFR [7].

\begin{tabular}{|l|c|c|c|c|c|c|}
\hline \multicolumn{1}{|c|}{ Страна } & $\mathbf{1 9 9 7}$ & $\mathbf{2 0 0 0}$ & $\mathbf{2 0 0 6}$ & $\mathbf{2 0 1 0}$ & $\mathbf{2 0 1 5}$ & $\mathbf{2 0 1 7}$ \\
\hline Южная Корея & $\ldots$ & $\ldots$ & $\ldots$ & 1239 & 1218 & 2435 \\
\hline США & 426 & 587 & 830 & 1112 & 1218 & 1200 \\
\hline Германия & 625 & 820 & 1220 & 1130 & 1147 & 1162 \\
\hline Япония & 1676 & 1686 & 1820 & 1436 & 1276 & 1158 \\
\hline Франция & 369 & 520 & 1160 & $\ldots$ & 940 & 1156 \\
\hline Испания & 252 & 520 & 970 & $\ldots$ & 883 & 990 \\
\hline Китай & $\ldots$ & $\ldots$ & $\ldots$ & 105 & 392 & 505 \\
\hline Италия & $\ldots$ & 850 & 1630 & 1229 & 877 & $\ldots$ \\
\hline Швеция & 470 & 540 & 590 & $\ldots$ & 734 & $\ldots$ \\
\hline Великобритания & 299 & 430 & 600 & 600 & 606 & $\ldots$ \\
\hline
\end{tabular}

Моделирование зависимости плотности роботов в автомобильной промышленности от макроэкономических показателей. В работе использовались данные IFR, World Bank [9], UNECE [10] за 2015 г. по 20 странам (США, Южная Корея. Китай, Япония и др.). Исследовалась зависимость плотности роботов от таких показателей, как ВВП на душу населения по паритету покупательской способности (ППС), доля затрат на НИОКР в ВВП, доля занятых в промышленности в общем количестве занятых, доля добавленной стоимости обрабатывающей промышленности в ВВП и др. Наиболее высокий коэффициент корреляции был получен для зависимостей, представленных на рис. 1. 
Дубинина В.В. Анализ плотности роботов в автомобильной.., стр. 115-121

Dubinina V.V. Analysis of robot density in the automotive industry, pp. 115-121

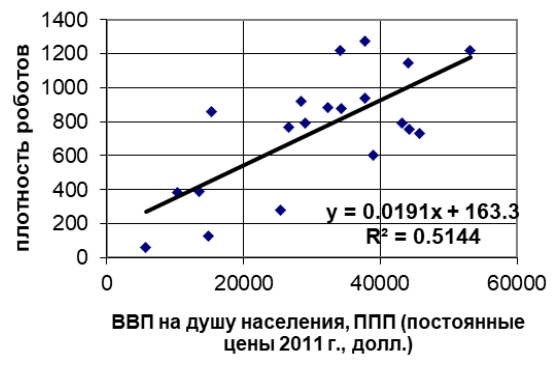

a)

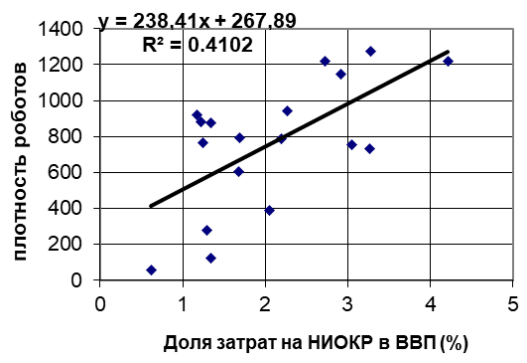

б)

Рис. 1. Зависимость плотности роботов от ВВП на душу населения по ППС (a), доли затрат на НИОКР в ВВП (б).

На основе проведенного анализа были разработаны многофакторные модели зависимости плотности роботов от ВВП на душу населения по ППС, доли механизмов и транспортного оборудования в добавленной стоимости обрабатывающей промышленности, доли экспорта промышленных товаров в общем объеме товарного экспорта рассматриваемых стран. Увеличение ВВП на душу населения по ППС на 1000 долл. приводит к росту плотности роботов на 16.8 ед. на 10 тыс. занятых в автомобильной промышленности:

$$
\mathrm{Y}=-125.65+11.77 * \mathrm{X}_{1}+0.02 * \mathrm{X}_{2}, \mathrm{R}^{2}=0.67
$$

где Y - плотность роботов в автомобильной промышленности, ед. на 10 тыс. занятых в автомобильной промышленности; $\mathrm{X}_{1}$ - механизмы и транспортное оборудование (\% от добавленной стоимости в обрабатывающей промышленности); $\mathrm{X}_{2}$ - ВВП на душу населения, ППС (постоянные цены 2011 г., долл.; в скобках здесь и далее t-статистики);

$$
\mathrm{Y}=-376.81+8.12 * \mathrm{X}_{3}+0.02 * \mathrm{X}_{2}, \mathrm{R}^{2}=0.63
$$

где $\mathrm{X}_{3}$ - доля экспорта промышленных товаров в общем объеме товарного экспорта (\%).

Влияние плотности роботов на выпуск автомобилей. Далее были построены модели, оценивающие влияние плотности роботов на производство легковых автомобилей в США, Германии и Японии с 2002 г. по 2017 г. В модели была введена фиктивная переменная, равная 1 в 2008 г. для Германии и в 2016 г. для Японии, и 0 в остальные годы. 


$$
\mathrm{Y}=\mathrm{a}^{*} \mathrm{x}+\mathrm{b}^{*} \mathrm{dum}+\mathrm{c}
$$

где $\mathrm{Y}$ - производство легковых автомобилей, млн. шт., $\mathrm{x}$ - плотность роботов, dum - фиктивная переменная, равная 1 в 2008 г. для Германии и в 2016 г. для Японии, и 0 в остальные годы.

Полученные для разных стран оценки параметров модели представлены в табл. 3.

Таблица 3. Оценка параметров модели (1).

\begin{tabular}{|l|c|c|c|c|}
\hline \multicolumn{1}{|c|}{ Страна } & $\mathbf{a}$ & $\mathbf{b}$ & $\mathbf{c}$ & $\mathbf{R}^{2}$ \\
\hline США & $\begin{array}{c}0.025 \\
(3.2)\end{array}$ & $\ldots$ & $\begin{array}{c}-19.0 \\
(2.1)\end{array}$ & 0.59 \\
\hline Япония & $\begin{array}{c}0.003 \\
(2.7)\end{array}$ & $\begin{array}{c}6.2 \\
(5.5)\end{array}$ & $\begin{array}{c}4.7 \\
(2.5)\end{array}$ & 0.74 \\
\hline Германия & $\begin{array}{c}0.014 \\
(3.2)\end{array}$ & $\begin{array}{c}1.1 \\
(3.1)\end{array}$ & $\begin{array}{c}-10.1 \\
(-2.1)\end{array}$ & 0.63 \\
\hline
\end{tabular}

Для всех стран получена положительная корреляция между плотностью роботов и количеством произведенных автомобилей за год. Рост плотности роботов в большей степени влияет на количество произведенных легковых автомобилей в США по сравнению с Германией и Японией.

Заключение. В результате проведенного исследования выявлено положительное влияние роста ВВП на душу населения по ППП, доли затрат на НИОКР в ВВП, доли механизмов и транспортного оборудования в добавленной стоимости обрабатывающей промышленности на плотность роботов, а также положительное влияние плотности роботов в автомобильной промышленности на производство легковых автомобилей. 


\section{СПИСОК ЛИТЕРАТУРЫ}

1. Варшавский A.E. Проблемы развития прогрессивных технологий: робототехника // МИР (Модернизациия. Инноваичи. Развитие). 2017. Т. 8, № 4s. C. 682-697.

2. Комкина T.А., Яркин А.П. Особенности использования бионики в медицинской робототехнике // Научно-практический журнал "Концепции". №1(37). 2018. C. 45-52.

3. Дубинина М.Г. Анализ показателей развития роботов для дуговой сварки (по поколениям) // Анализ и моделирование экономических и социальных процессов / Математика. Компьютер. Образование: Сб. научн. трудов (выпуск 25). № 2. - М.-Ижевск: НИЦ «Регулярная и хаотическая динамика», 2018. C. 88-96.

4. Варшавский А.Е., Дубинина В.В. Основные тенденции изменения техникоэкономических показателей промышленных роботов // Национальные интересы: приоритеты и безопасность. 2018. Т. 14, № 10. С.1916-1935. DOI: 10.24891/ni.14.10.1916

5. Ежеленко В. Промышленная робототехника в России. Краткий обзор роботизации, проблем и перспектив внедрения промышленных роботов на отечественных предприятиях. URL: http://www.umpro.ru/templates/art_print.php?art_id_1=395

6. Karabegović I., Husak E. The Fourth Industrial Revolution and the Role of Industrial Robots: A with Focus on China // Journal of Engineering and Architecture. 2018. Vol. 6, No. 1. P. 110-117. DOI: 10.15640/jea.v5n2a9

7. IFR (International Federation of Robotics). URL: https://www.ifr.org/industrialrobots/statistics/

8. De Backer K., De Stefano T., Menon C., Ran Suh J. Industrial robotics and the global organization of production. OECD Science, Technology and Industry Working Papers. No. 2018/03.

9. World Bank. URL: https://data.worldbank.org/ 10. UNECE. URL: https://w3.unece.org/PXWeb/en

\section{ANALYSIS OF ROBOT DENSITY IN THE AUTOMOTIVE INDUSTRY}

\section{Dubinina V.V.}

This article discusses the dependence of the robot density in the automotive industry on macroeconomic indicators, as well as the effect of robotization on car production in the United States, Germany and Japan. 